\title{
Prevalence of Hepatitis E Virus Antibodies Among Blood Donors: A Systematic Review and Meta-Analysis
}

\author{
Vinicius Lins Ferreira, ${ }^{1}$ Vanessa Rodrigues de Souza, ${ }^{1}$ Dominique Araujo Muzzillo, ${ }^{2}$ and Roberto \\ Pontarolo ${ }^{1, *}$ \\ ${ }^{1}$ Department of Pharmacy, Pharmaceutical Sciences Postgraduate Program, Universidade Federal do Parana, Curitiba, Brazil \\ ${ }^{2}$ Department of Internal Medicine, Hospital de Clinicas, Universidade Federal do Parana, Curitiba, Brazil \\ "Corresponding author: Roberto Pontarolo, Department of Pharmacy, Universidade Federal do Parana, Av Pref Lothario Meissner, 632, Jardim Botanico, 80210170 - Curitiba, PR - \\ Brasil. Tel: +55-4133604094, E-mail: pontarolo@ufpr.br
}

Received 2016 October 07; Revised 2017 January 10; Accepted 2017 January 30.

\begin{abstract}
Context: Hepatitis E virus (HEV) is well-known to be transmitted by the fecal-oral route. In addition, several studies in Europe and Asia had reported potential HEV transmission associated with blood transfusion, but this route is still uncertain.

Objective: The aim of this study was to estimate the anti-HEV IgG seroprevalence among blood donors around the world using the Bayesian-based methods.

Evidence Acquisition: A systematic review was performed using the PubMed/Medline, Scopus, Web of Science and Cochrane Library databases using the terms "prevalence", "hepatitis E" and "blood donors". Studies with a timeframe from inception to March 2016, in Roman characters, that had outcomes of interest such as prevalence of IgG antibodies were included. The estimation of anti-HEV IgG (presented as the event rate and 95\% confidence intervals, CI) was performed using a Bayesian-based random effect model using the Comprehensive Meta-Analysis software, version 2. Pairwise meta-analyses and chi-square tests were used to assess significant differences between different sexes and ages.

Results and Conclusions: Of the retrieved studies, 71 met the inclusion criteria, comprising a total of 113316 blood donors. The prevalence rate was statistically significant in males and over 40 years old donors $(\mathrm{P}<0.05)$. The overall estimation of the antiHEV IgG prevalence was 0.058 (CI 95\%: 0.049 - 0.068). Subgrouping by region, the estimates were higher for Asia and the Middle East, respectively: 0.113 (CI 95\%: 0.040 - 0.278) and 0.112 (CI 95\%: 0.081 - 0.152). Europe, Africa, Oceania and America had an estimated prevalence between 0.014and 0.088. A relevant prevalence of anti-HEV IgG among blood donors was found worldwide, especially in Asia and the Middle East and in males and donors over 40 years. This review reinforces the view that HEV parenteral route infection needs to be further investigated and possibly screened for in transfused blood.
\end{abstract}

Keywords: Hepatitis E, Systematic Review, Blood Donors

\section{Context}

Hepatitis E virus (HEV) is responsible for an emergent health problem worldwide and it is estimated that it can cause 20 million infections and more than 50000 hepatitis $E$ related deaths per year. Hepatitis E virus is a small RNA virus that belongs to genus Hepevirus of the family Hepeviridae $(1,2)$. For many years, hepatitis E was recognized as an infection of tropical countries, especially developing and undeveloped countries, caused by contaminated drinking water and food. In developed countries, HEV infection was thought to be travel associated, but many studies reported autochthonous cases (3-5).

Hepatitis E virus is well-known to be transmitted via the fecal-oral route. The association of blood and HEV transmission is controversial; so, this route is still uncertain $(6,7)$. Previous studies have shown transmission through parenteral routes (8-11). Additionally, transfusion- transmitted HEV infections have been presented in case study reports (12-14).

After HEV exposure, clinical signs and symptoms appear in two to nine weeks, which include myalgia, arthralgia, anorexia, hepatomegaly, fever, weakness, vomiting and jaundice. Hepatitis E virus can result in acute liver failure in rare and severe cases. Chronic cases are also uncommon, but may occur specially in immunosuppressed patients $(15,16)$. There are many laboratory tests for HEV infection diagnosis, which can be classified into direct (detection of HEV or viral protein by the polymerase chain reaction or enzyme immunoassay) and indirect methods (detection of anti-HEV antibodies) (17,18).

The presence of IgM anti-HEV antibodies is associated with recent $\mathrm{HEV}$ infection. In addition, the detection of anti-HEV IgG antibodies provides the evidence of recent or remote exposure to HEV. In this way, both antibodies are important for the HEV infection diagnosis and can be asso- 
ciated with a permanent infection $(17,18)$.

A previous review investigated the prevalence of antiHEV in blood donors. However, it included only studies published between 2009 and 2014 and no estimation of the prevalence of IgG antibodies was conducted (19).

In general, screening tests are not performed for HEV in blood donors, and this could be associated with silent transmission. Gathered data from epidemiological studies may support evidence regarding the necessity of HEV screening in blood products, especially in regions with a high prevalence $(20,21)$. Therefore, this systematic review aimed at estimating the seroprevalence of anti-HEV antibodies among blood donors worldwide and regionally using Bayesian-based methods.

\section{Methods}

\subsection{Systematic Review and Eligibility Criteria}

This systematic review (PROSPERO registration number CRD42016033926) was conducted following the preferred reporting items for systematic reviews and metaanalyses (PRISMA) and Cochrane collaboration recommendations, so that all steps were conducted by two reviewers independently and discrepancies were decided by consensus with a third author.

We searched the PubMed/Medline, Scopus, Web of Science and Cochrane Library electronic databases for all reports that contained data for anti-HEV IgG seroprevalence among blood donors (studies published up to March 2016). The search strategy included the terms "seroprevalence", "hepatitis E" and "blood donors" and results were included regardless of design or sample size (see complete search strategies in Appendix 1 in the supplementary file).

Studies that did not report the anti-HEV IgG seroprevalence, those that were published in non-Roman characters, and reviews were excluded. Additionally, studies investigating blood donors only with an elevated alanine aminotransferase and/or plasma minipools were not included.

\subsection{Data Extraction and Quality Assessment}

The relevant data extracted from each study included: (a) baseline characteristics (number of patients, gender, age and country); (b) HEV antibodies (IgM and IgG); and (c) the method used for HEV detection. These data were collected in a previously developed spreadsheet from Excel.

Quality appraisal of the included studies was assessed according to previously published criteria (22), which consider four sources of bias related to the study: participation, study attrition, measurement of outcomes and analysis approaches. According to it, the sources of bias are scored in "yes", "partly", "no" or "unsure”.

\subsection{Data Analysis}

The prevalence rate of HEV antibodies among blood donors and 95\% confidence intervals (CI) were estimated for each study. Data were pooled with a random-effect model for overall and subgroup estimations, which were performed by regions (South America, North America, Central America, Europe, Africa, Oceania, Middle East and Asia) and by country. Two subanalyses were conducted according to the year that each study was published:1)1992 - 2006 and 2) 2007 - 2016 (last ten years).

Additionally, a meta-regression analysis was performed using a linear random-effects model to relate the event rate to the year that the studies were published. These analyses were performed using the Comprehensive Meta-Analysis software, version 2.

Based on the previous evidence $(23,24)$, we also conducted two pairwise meta-analyses to compare the prevalence of HEV antibodies by gender (male versus female) and age ( $<40$ versus $>40$ years old). Data from each dichotomous outcome were pooled and presented as odds ratio (OR) with a 95\% CI, using forest plots. Heterogeneity was assessed using the $\mathrm{I}^{2}$ statistical test, which is considered significantly high when $\mathrm{I}^{2}>50 \%$. The meta-analyses were conducted using the Review Manager, version 5.3. Finally, we also used a chi-square test to verify significant differences between the gender and age groups. This analysis was performed in Statistical Package for Social Science (SPSS) version 19.

\section{Results}

\subsection{Search Results and Characteristics of Included Studies}

After exclusion of duplicates, a total of 2239 potential studies were retrieved in the electronic searches and were screened by title and abstract (Figure 1). After a full-text analysis of the 154 remaining articles, 83 were excluded, resulting in 71 included studies (Appendix 2 in the supplementary file). Of these, 31 studies related to countries in Europe, eight to Asia, eight to South America, eight to North America, seven to the Middle East, six to Africa, two to Oceania and one to Central America. They were conducted in the time period 1992 to 2016 . Only few studies reported data for HEV IgM antibodies, and therefore made impossible the analysis by statistical methods. In this way, analyses were performed only for HEV IgG antibodies.

\subsection{Prevalence of Hepatitis E Virus IgG Antibodies According to Region and Period of Time}

The studies included data from 117276 blood donors. The estimated pooled anti-HEV IgG seroprevalence across all studies was 0.058 (CI 95\%: 0.049-0.068) (Figure 2). 


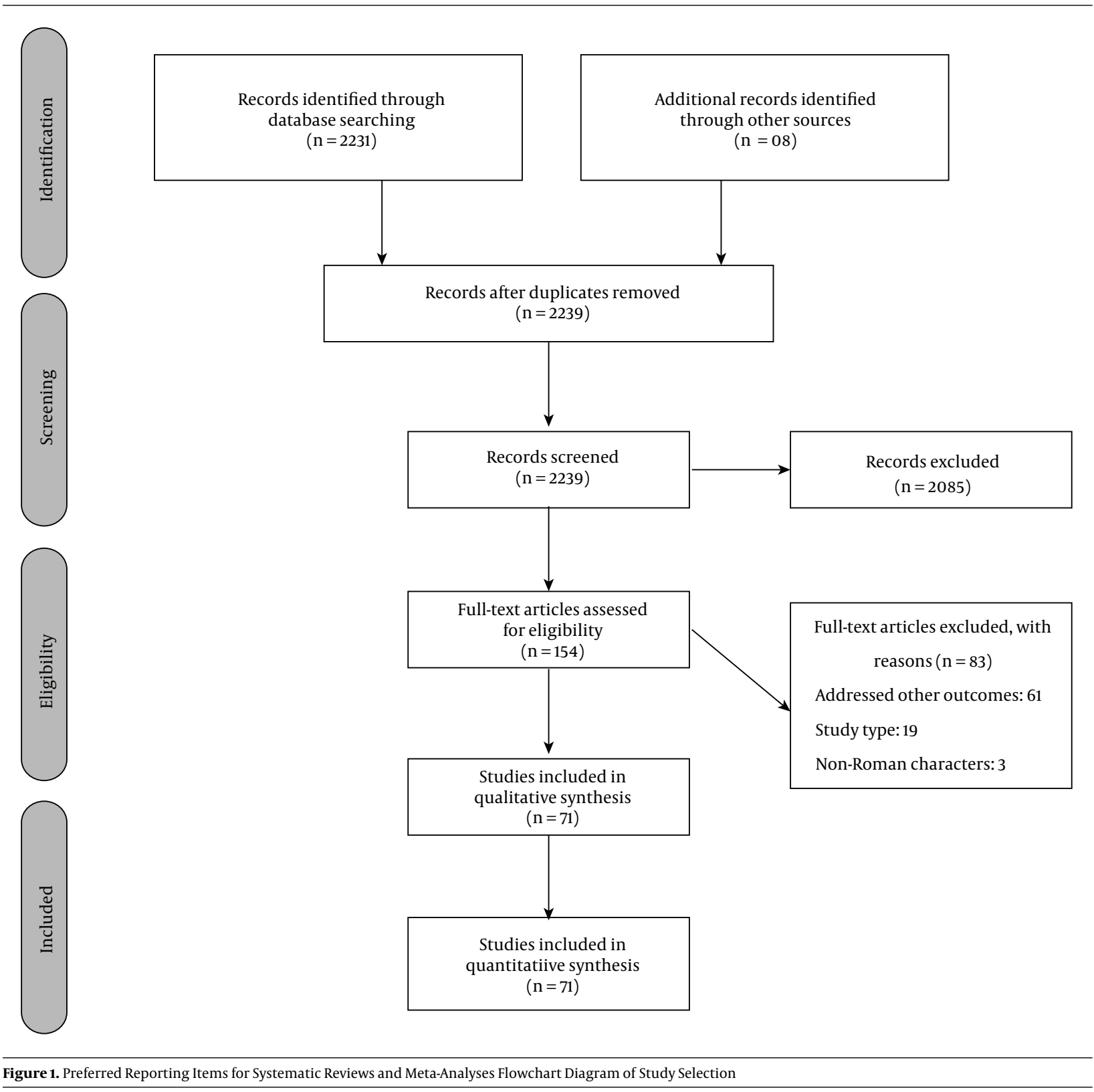

Subgrouping by region, the estimation of prevalence was higher in Asia at 0.113 (CI 95\%: 0.04-0.278) and in the Middle East at 0.112 (CI 95\%: 0.081 - 0.152). Estimates for other regions ranged from 0.014 (CI 95\%: 0.009-0.023) in Central America to 0.088 (CI 95\%: 0.034 - 0.212) in Africa. By country, the estimated prevalence was higher in China at 0.279 (CI 95\%: 0.197 - 0.380) and Egypt at 0.453 (CI 95\%: 0.356 - 0.553) (more details are presented in Appendix 3 in the supplementary file).

As it were included data over the last 24 years (1992 2016), subanalysis was performed in two periods of time:
1) 1992 - 2006, and 2) the last ten years (2007 - 2016). From 1992 - 2006 (Figure 3, 28 studies), the overall prevalence was 0.030 (CI 95\%: 0.023 - 0.039), with a higher incidence in Africa, Middle East and Asia. On the other hand, the overall prevalence (0.076 CI 95\%: 0.063 - 0.091) was higher in the last ten years (Figure 4, 43 studies). Asia and Middle East had high incidence rates, followed by Europe, North America and Africa. Developed regions such as Europe and North America had an increase in the number of cases in the last ten years.

Meta-regression(Figure 5) was used to analyze whether 


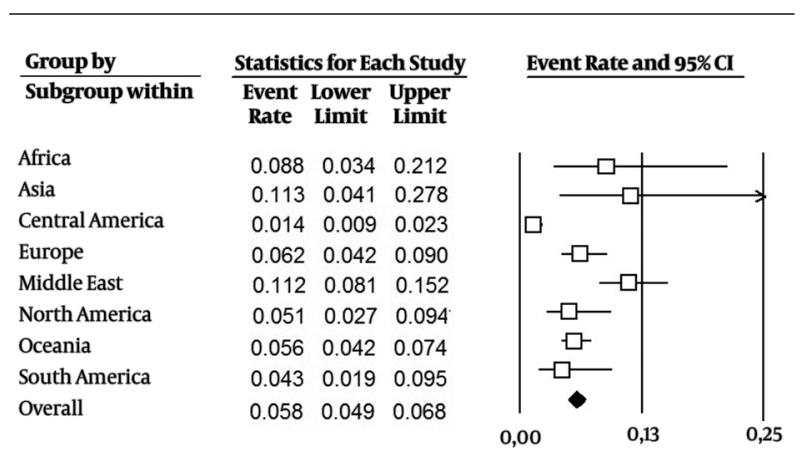

Figure 2. Estimated Pooled Anti-HEV IgG Seroprevalence in Studied Regions and Overall

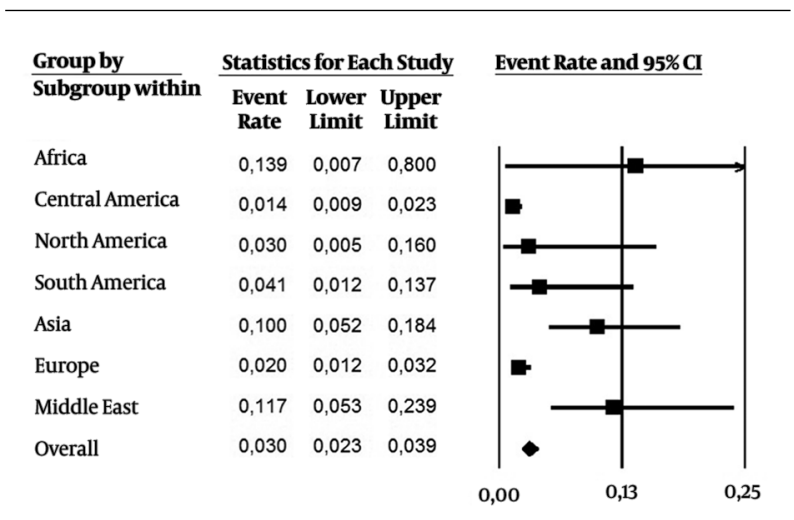

Figure 3. Estimated Pooled Anti-HEV IgG Seroprevalence Including Studies During $1992-2006$

\begin{tabular}{|c|c|c|c|c|}
\hline \multirow{2}{*}{$\begin{array}{l}\text { Group by } \\
\text { Subgroup within }\end{array}$} & \multicolumn{3}{|c|}{ Statistics for Each Study } & \multirow[t]{2}{*}{ Event Rate and 95\% C } \\
\hline & $\begin{array}{l}\text { Event } \\
\text { Rate }\end{array}$ & $\begin{array}{l}\text { Lower } \\
\text { Limit }\end{array}$ & $\begin{array}{l}\text { Upper } \\
\text { Limit }\end{array}$ & \\
\hline Africa & 0,070 & 0,032 & 0,145 & \\
\hline North America & 0,083 & 0,042 & 0,157 & \\
\hline South America & 0,046 & 0,015 & 0,132 & \\
\hline Asia & 0,145 & 0,033 & 0,460 & \\
\hline Europe & 0,101 & 0,069 & 0,144 & \\
\hline Oceania & 0,056 & 0,042 & 0,074 & $=$ \\
\hline Middle East & 0,109 & 0,071 & 0,162 & \\
\hline \multirow[t]{2}{*}{ Overall } & 0,076 & 0,063 & 0,091 & \\
\hline & & & & 0,00 \\
\hline
\end{tabular}

Figure 4. Estimated Pooled Anti-HEV IgG Seroprevalence Including Studies Published in the Last Ten Years

there was rise in event rates during 1992 - 2016. In general, a small increase of the number of events per year $(0.05$ events rate/year) was found.

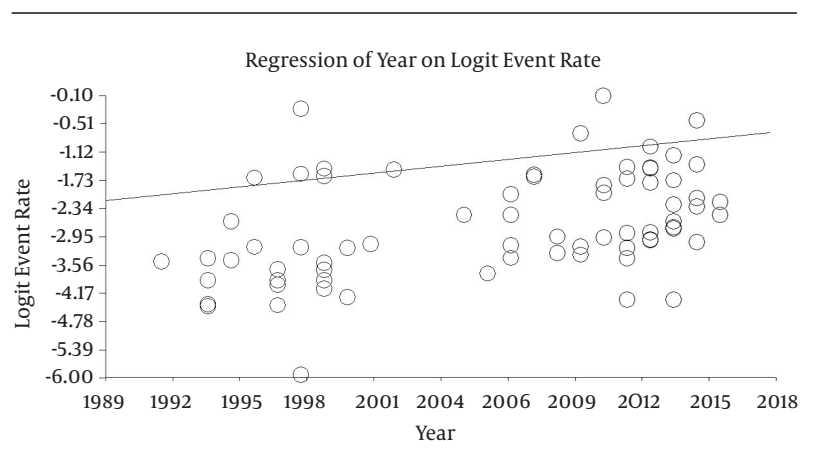

Figure 5. Meta-Regression of Rates of Events During 1992-2016

3.3. Pairwise Meta-Analysis: Prevalence of Hepatitis E Virus IgG Antibodies by Gender and Age

Pairwise meta-analyses of gender (male versus female) and age ( $<40$ versus $>40$ years old) were performed respectively with 24 and 12 studies (Table 1). Anti-HEV IgG seroprevalence was higher in males at 1.18 (CI 95\%: 1.01-1.38) and in blood donors over 40 years at 0.33 (CI 95\%: 0.26 0.43). Forest plots are shown in Appendix 4 in the supplementary file. Heterogeneity was low for both analyses $\left(\mathrm{I}^{2}\right.$ $<50 \%$ ). A similar result was observed using the chi-square test (Table 2), the prevalence was statistically significant in males and donors over 40 years $(\mathrm{P}<0.05)$.

\subsection{Quality Assessment of Included Studies}

The methodological quality assessment (Appendix 5 in the supplementary file) showed that in general the included studies in this systematic review presented valuable data. Nevertheless, it was observed in some studies a lack of more detailed and precise information. As a main consequence, for instance, the meta-analysis (by gender and age) had a diminished number of studies.

The majority of the studies presented unsure information in study participation source of bias. In general, it was observed that there were no concerns in author's studies to justify it. A great number of the studies also presented unsure information in the study attrition source of bias. As a consequence, when reporting the outcomes, there were a relevant number of studies that partly reported it. The overall analysis approaches adopted by the studies well evaluated.

\section{Discussion}

Nowadays, hepatitis $\mathrm{E}$ is known to be a worldwide disease, mainly associated with inadequate sanitation and poor hygiene practices. Outbreaks are associated with rainy seasons, floods and overcrowding (25). In agreement 
Table 1. Pairwise Meta-Analysis of Gender (Male Versus Female) and Age $(<40$ Versus $>40$ )

\begin{tabular}{lcccc}
\hline Outcome & Studies (Number of Reference) & Participants & Effect Estimate (95\% & CI) \\
\hline Female vs. Male & 24 & 34,418 & $1.18(1.01-1.38)$ & 0.04 \\
$>\mathbf{4 0}$ vs. $<\mathbf{4 0}$ & 12 & 16,874 & $0.33(0.26-043)$ & 33 \\
\hline
\end{tabular}

${ }^{\mathrm{a}}$ Value are expressed as number percent.

Table 2. Antihepatitis E Virus Seroprevalence IgG Among Different Sex and Age

\begin{tabular}{l|c|c|c}
\hline \multirow{2}{*}{ Outcome } & \multicolumn{2}{|c|}{ Anti-HEV seroprevalence } & \multirow{2}{*}{ P Value } \\
\cline { 2 - 3 } & IgG + & IgG - & \\
\hline \multirow{2}{*}{ Male } & 1034 & 17903 & \multirow{2}{*}{$\mathrm{P}<0.05$} \\
\cline { 1 - 3 } Female & 579 & 14346 & \multirow{2}{*}{$\mathrm{P}<0.05$} \\
\hline$<\mathbf{4 0}$ & 272 & 8412 & \\
\hline$>\mathbf{4 0}$ & 673 & 7517 & \\
\hline
\end{tabular}

Abbreviation: HEV, Hepatitis E Virus.

with previous studies (2), Asia showed the highest antiHEV-IgG seroprevalence among regions.

However, for many years, Europe was thought to be a nonendemic region for HEV, but several HEV cases unrelated to travel history have been reported $(26,27)$. A previous study also demonstrated potential zoonotic transmission of HEV in a European country (28). Our comparison of the rates of events before and after 2006 showed an increase in the number of cases in developed regions, such as Europe, and North America. This evidence suggests that HEV is spreading worldwide, not only in developing countries, but also more in developed countries than previously thought $(29,30)$.

Although HEV infection is generally mild and selflimiting, in some cases it can become a severe disease, especially in pregnant women and immunocompromised, transplanted and HIV-infected patients, where it can cause chronic infection, fulminant hepatitis and serious extrahepatic symptoms (31). Previous studies have found that individuals had already acquired HEV infection following blood transfusions, including patients in nonendemic regions $(10,11,13,32)$.

Responsible agencies should consider HEV screening in blood transfusions to avoid its infection and complications, especially in endemic areas where a higher risk is present, considering that every effort to minimize the potential of the transfusion-transmitted disease is valuable $(31,33,34)$.

Testing for hepatitis E has significantly improved over the years $(35,36)$, but the variability in sensitivity and speci- ficity of available screening tests makes data analysis difficult (37). Another factor that contributes to the lack of information about the frequency of HEV transmission by the transfusion route is underreported cases (33), which are possible associated with subclinical infections.

Finally, meta-regression illustrated a slight increase in the event rate from 1992 to 2016. The present study found the anti-HEV IgG seroprevalence to be higher in male than female donors in agreement with previous studies (38-41). The rate also increased with age in agreement with previous findings (37, 41-43). In this way, HEV screening in blood transfusions also should be considerate for male and over 40 years old blood donors, as they appears as a risk group.

Our study presented some limitations. Different tests for HEV antibodies' detection were used by the studies included in this systematic review, but a previous study concluded that in general the tests that were evaluated were similar for HEV IgG detection, but they could differ in some points (44). Furthermore, the included studies would possibly differ in baseline characteristics (number of patients, gender, and age).

\subsection{Conclusions}

The results of this study demonstrate a significant prevalence of anti-HEVIgG among blood donors, especially in males and donors over 40 years, suggesting the screening of HEV in blood transfusions should be considered to avoid complications. Asia and Middle East had the highest incidence of anti-HEV IgG, probably caused by inadequate infrastructure conditions. Moreover, HEV infection by parenteral routes needs to be further investigated.

\section{Supplementary Material}

Supplementary material(s) is available here.

\section{Footnotes}

Authors' Contribution: Vinicius Lins Ferreira designed the study, extracted and analyzed the data, performed quality evaluation, wrote the first draft of the manuscript and approved the final version of the manuscript. Vanessa 
Rodrigues de Souza designed the study, performed the statistical analysis, analyzed the data, wrote the first draft of the manuscript and approved the final version of the manuscript. Dominique Araujo Muzzillo conceptualized and designed the study, supervised the project and approved the final version of the manuscript. Roberto Pontarolo conceptualized and designed the study, supervised the project and approved the final version of the manuscript.

Financial Disclosure: No conflicts of interest have been declared.

\section{Funding/Support: None declared.}

\section{References}

1. Lozano R, Naghavi M, Foreman K, Lim S, Shibuya K, Aboyans V, et al. Global and regional mortality from 235 causes of death for 20 age groups in 1990 and 2010: a systematic analysis for the Global Burden of Disease Study 2010. Lancet. 2012;380(9859):2095-128. doi: 10.1016/S0140-6736(12)61728-0. [PubMed: 23245604].

2. Rein DB, Stevens GA, Theaker J, Wittenborn JS, Wiersma ST. The global burden of hepatitis E virus genotypes 1 and 2 in 2005. Hepatology. 2012;55(4):988-97. doi: 10.1002/hep.25505. [PubMed: 22121109].

3. Ben-Ayed Y, Hannachi H, Ben-Alaya-Bouafif N, Gouider E, Triki H, Bahri O. Hepatitis E virus seroprevalence among hemodialysis and hemophiliac patients in Tunisia (North Africa). J Med Virol. 2015;87(3):441-5. doi: 10.1002/jmv.24082. [PubMed: 25331682].

4. Fischer C, Hofmann M, Danzer M, Hofer K, Kaar J, Gabriel C. Seroprevalence and Incidence of hepatitis $\mathrm{E}$ in blood donors in Upper Austria. PLoS One. 2015;10(3):e0119576. doi: 10.1371/journal.pone.0119576. [PubMed: 25751574].

5. Dreier J, Juhl D. Autochthonous hepatitis e virus infections: a new transfusion-associated risk? Transfus Med Hemother. 2014;41(1):29-39. doi: 10.1159/000357098. [PubMed: 24659945].

6. Ehteram H, Ramezani A, Eslamifar A, Sofian M, Banifazl M, Ghassemi $S$, et al. Seroprevalence of Hepatitis E Virus infection among volunteer blood donors in central province of Iran in 2012. Iran J Microbiol. 2013;5(2):172-6. [PubMed: 23825737].

7. Hewitt PE, Ijaz S, Brailsford SR, Brett R, Dicks S, Haywood B, et al Hepatitis $\mathrm{E}$ virus in blood components: a prevalence and transmission study in southeast England. Lancet. 2014;384(9956):1766-73. doi: 10.1016/S0140-6736(14)61034-5. [PubMed: 25078306].

8. Matsubayashi K, Nagaoka Y, Sakata H, Sato S, Fukai K, Kato T, et al. Transfusion-transmitted hepatitis E caused by apparently indigenous hepatitis E virus strain in Hokkaido, Japan. Transfusion. 2004;44(6):934-40. doi: 10.1111/j.1537-2995.2004.03300.x. [PubMed: 15157263].

9. Matsubayashi K, Kang JH, Sakata H, Takahashi K, Shindo M, Kato M, et al. A case of transfusion-transmitted hepatitis E caused by blood from a donor infected with hepatitis E virus via zoonotic food-borne route. Transfusion. 2008;48(7):1368-75. doi: 10.1111/j.1537-2995.2008.01722.x. [PubMed: 18651907].

10. Boxall E, Herborn A, Kochethu G, Pratt G, Adams D, Ijaz S, et al. Transfusion-transmitted hepatitis $\mathrm{E}$ in a 'nonhyperendemic' country. Transfus Med. 2006;16(2):79-83. doi: 10.1111/j.1365-3148.2006.00652.x. [PubMed: 16623913].

11. Hauser L, Roque-Afonso AM, Beyloune A, Simonet M, Deau Fischer B, Burin des Roziers N, et al. Hepatitis E transmission by transfusion of Intercept blood system-treated plasma. Blood. 2014;123(5):796-7. doi: 10.1182/blood-2013-09-524348. [PubMed: 24482503].
12. Adlhoch C, Kaiser M, Pauli G, Koch J, Meisel H. Indigenous hepatitis E virus infection of a plasma donor in Germany. Vox Sang. 2009;97(4):303-8. doi: 10.1111/j.1423-0410.2009.01211.x. [PubMed 19555366].

13. Colson P, Coze C, Gallian P, Henry M, De Micco P, Tamalet C. Transfusion-associated hepatitis E, France. Emerg Infect Dis 2007;13(4):648-9. doi: 10.3201/eid1304.061387. [PubMed: 17561564].

14. Matsui T, Kang JH, Matsubayashi K, Yamazaki H, Nagai K, Sakata H, et al. Rare case of transfusion-transmitted hepatitis E from the blood of a donor infected with the hepatitis E virus genotype 3 indigenous to Japan: Viral dynamics from onset to recovery. Hepatol Res. 2015;45(6):698-704. doi: 10.1111/hepr.12390. [PubMed: 25041213].

15. Mirazo S, Ramos N, Mainardi V, Gerona S, Arbiza J. Transmission, diagnosis, and management of hepatitis E: an update. Hepat Med. 2014;6:45-59. doi: 10.2147/HMER.S63417. [PubMed: 24966702]

16. Perez-Gracia MT, Suay B, Mateos-Lindemann ML. Hepatitis E: an emerging disease. Infect Genet Evol. 2014;22:40-59. doi: 10.1016/j.meegid.2014.01.002. [PubMed: 24434240].

17. Fujiwara S, Yokokawa Y, Morino K, Hayasaka K, Kawabata M, Shimizu T. Chronic hepatitis E: a review of the literature. J Viral Hepat 2014;21(2):78-89. doi: 10.1111/jvh.12156. [PubMed: 24383921].

18. Aggarwal R. Diagnosis of hepatitis E. Nat Rev Gastroenterol Hepatol. 2013;10(1):24-33. doi:10.1038/nrgastro.2012.187. [PubMed: 23026902].

19. World Health Organization (WHO). . A systematic review on hepatitis E virus globally 2014. Available from: http://www.who.int/ immunization/sage/meetings/2014/october/7_summary_HEV_ systematic_review.pdf.

20. Naeimi B, Mazloom Kalimani F, Pourfatolah AA, Azimzadeh M, Mankhian A, Akbarzadeh S, et al. Hepatitis E Virus Seroprevalence Among Blood Donors in Bushehr, South of Iran. Hepat Mon. 2015;15(11):ee29219. doi: 10.5812/hepatmon.29219. [PubMed: 26834784].

21. Hesamizadeh K, Sharafi H, Keyvani H, Alavian SM, Najafi-Tireh Shabankareh A, Sharifi Olyaie R, et al. Hepatitis A Virus and Hepatitis E Virus Seroprevalence Among Blood Donors in Tehran, Iran. Hepat Mon. 2016;16(1):ee32215. doi:10.5812/hepatmon.32215. [PubMed: 27110256].

22. Hayden JA, Cote P, Bombardier C. Evaluation of the quality of prognosis studies in systematic reviews. Ann Intern Med. 2006;144(6):427-37. doi: 10.7326/0003-4819-144-6-200603210-00010. [PubMed: 16549855].

23. Ahmed A, Ali IA, Ghazal H, Fazili J, Nusrat S. Mystery of hepatitis e virus: recent advances in its diagnosis and management. Int J Hepatol. 2015;2015:872431. doi: 10.1155/2015/872431. [PubMed: 25692043].

24. Zhuang W, Ding X, Lyu C, Xiang L, Teng H, Li J. Hepatitis E virus seroprevalence among blood donors in Jiangsu Province, East China Int J Infect Dis. 2014;26:9-11. doi: 10.1016/j.ijid.2014.04.022. [PubMed: 24981426].

25. Bartnof HS, editor. Hepatitis E emerges as a significant cause of liver inflammation worldwide. 10th International symposium on viral hepatitis and liver diseases. 2000; Atlanta.

26. Folgado Alberto S, Pires S, Félix J, Figueiredo A, Silva L, Franco M. Prevalence of Hepatitis E virus in a non endemic population-prospective study. GE-J Port Gastrenterol. 2009;16:191-7.

27. Mansuy JM, Legrand-Abravanel F, Calot JP, Peron JM, Alric L, Agudo $S$, et al. High prevalence of anti-hepatitis E virus antibodies in blood donors from South West France. J Med Virol. 2008;80(2):289-93. doi: 10.1002/jmv.21056. [PubMed: 18098159].

28. van der Poel WH, Verschoor F, van der Heide R, Herrera MI, Vivo A Kooreman M, et al. Hepatitis E virus sequences in swine related to sequences in humans, The Netherlands. Emerg Infect Dis. 2001;7(6):9706. doi: 10.3201/eid0706.010608. [PubMed: 11747723].

29. Abe K, Li TC, Ding X, Win KM, Shrestha PK, Quang VX, et al. International collaborative survey on epidemiology of hepatitis $E$ virus in 11 countries. Southeast Asian J Trop Med Public Health. 2006;37(1):90-5. [PubMed: 16771218] 
30. Dalton HR, Bendall R, Ijaz S, Banks M. Hepatitis E: an emerging infection in developed countries. Lancet Infect Dis. 2008;8(11):698-709. doi: 10.1016/S1473-3099(08)70255-X. [PubMed: 18992406].

31. Pawlotsky JM. Hepatitis E screening for blood donations: an urgent need? Lancet. 2014;384(9956):1729-30. doi: 10.1016/S01406736(14)61187-9. [PubMed: 25078305].

32. Haim-Boukobza S, Ferey MP, Vetillard AL, Jeblaoui A, Pelissier E, Pelletier G, et al. Transfusion-transmitted hepatitis E in a misleading context of autoimmunity and drug-induced toxicity. J Hepatol. 2012;57(6):1374-8. doi:10.1016/j.jhep.2012.08.001. [PubMed: 22885386].

33. Anand AC, Singh KJ, Sharma P, Kumar S, Gupta RM. Incidence of Hepatitis E Virus Infection in Recipients of Blood or Blood Products Transfusion. Med J Armed Forces India. 2010;66(3):204-7. doi: 10.1016/S03771237(10)80037-1. [PubMed: 27408301]

34. Parsa R, Adibzadeh S, Behzad Behbahani A, Farhadi A, Yaghobi R, Rafiei Dehbidi GR, et al. Detection of Hepatitis E Virus Genotype 1 Among Blood Donors From Southwest of Iran. Hepat Mon. 2016;16(6):ee34202. doi: 10.5812/hepatmon.34202. [PubMed 27630719].

35. Favorov MO, Fields HA, Purdy MA, Yashina TL, Aleksandrov AG, Alter MJ, et al. Serologic identification of hepatitis E virus infections in epidemic and endemic settings. J Med Virol. 1992;36(4):246-50. [PubMed: 1578218].

36. Paul DA, Knigge MF, Ritter A, Gutierrez R, Pilot-Matias T, Chau KH et al. Determination of hepatitis E virus seroprevalence by using recombinant fusion proteins and synthetic peptides. J Infect Dis. 1994;169(4):801-6. [PubMed: 8133095].

37. Aminiafshar S, Alimagham M, Gachkar L, Yousefi F, Attarchi Z. Anti hepatitis E virus seropositivity in a group of blood donors. Iran JPublic
Health. 2004;33(4):53-6.

38. Assarehzadegan MA, Shakerinejad G, Amini A, Rezaee SA. Seroprevalence of hepatitis $\mathrm{E}$ virus in blood donors in Khuzestan Province, southwest Iran. Int J Infect Dis. 2008;12(4):387-90. doi: 10.1016/j.ijid.2007.09.015. [PubMed: 18063401].

39. Juhl D, Baylis SA, Blumel J, Gorg S, Hennig H. Seroprevalence and incidence of hepatitis E virus infection in German blood donors. Transfusion. 2014;54(1):49-56. doi: 10.1111/trf.12121. [PubMed: 23441647].

40. Kaufmann A, Kenfak-Foguena A, Andre C, Canellini G, Burgisser P, Moradpour D, et al. Hepatitis E virus seroprevalence among blood donors in southwest Switzerland. PLoS One. 2011;6(6):ee21150. doi: 10.1371/journal.pone.0021150. [PubMed: 21701586].

41. Takeda H, Matsubayashi K, Sakata H, Sato S, Kato T, Hino S, et al. A nationwide survey for prevalence of hepatitis $\mathrm{E}$ virus antibody in qualified blood donors in Japan. Vox Sang. 2010;99(4):307-13. doi: 10.111/j.1423-0410.2010.01362.x. [PubMed: 20576022].

42. Houcine N, Jacques R, Salma F, Anne-Gaelle D, Amin S, Mohsen H, et al. Seroprevalence of hepatitis $E$ virus infection in rural and urban populations, Tunisia. Clin Microbiol Infect. 2012;18(5):E119-21. doi: 10.1111/j.1469-0691.2012.03793.x. [PubMed: 22404115].

43. Meng XJ, Wiseman B, Elvinger F, Guenette DK, Toth TE, Engle RE, et al. Prevalence of antibodies to hepatitis $E$ virus in veterinarians working with swine and in normal blood donors in the United States and other countries. J Clin Microbiol. 2002;40(1):117-22. doi: 10.1128/JCM.40.1.117122.2002. [PubMed: 11773103].

44. Avellon A, Morago L, Garcia-Galera del Carmen M, Munoz M, Echevarria JM. Comparative sensitivity of commercial tests for hepatitis $\mathrm{E}$ genotype 3 virus antibody detection. J Med Virol. 2015;87(11):1934-9. doi: 10.1002/jmv.24251. [PubMed: 25959136]. 